\title{
The Impact of the New Media on Sex Education of Chinese Parents Having on Their Children
}

\begin{abstract}
Xueli Wang
Friends Select School

shirleywxueliw@gmail.com

ABSTRACT

As the cases of child sexual abuse grow, the issue of sex education for children is gaining attention on a global scale. The paper first compares the current status of sex education for children in China with that in the United State, especially in America, India, and Spain, then identifies private accounts, We-media, and websites that provide information on children's sex education in China. The researcher used a semi-structured in-depth interview strategy on six parents who have school-age children and two sex educators, with recorded and analyzed transcripts. The paper concludes that new media have had a significant impact in promoting parents' renewed attitudes toward sex education and have provided parents as well as children with a variety of resources for learning about children's sex education.
\end{abstract}

Keywords: Children's sexual education, new media, sexual abuse, comprehensive sexuality education.

\section{INTRODUCTION}

With the reform and openness of China, the attention and perception of Chinese parents towards children's sex education have changed, and the crime subjects in the cases of child sexual abuse in China are the number of the cases on child sexual abuse concluded by the national court was as high as 10,782 , with an average of more than seven cases appealed each day; in other words, at least seven children were harmed each day. 433 cases of sexual abuse of children were publicly reported in 2017 .

Girls Protection recommends that a mandatory reporting system for cases of abuse against minors should be fully established. Based on the existing pilot, sum up the experience, optimize the scope of compulsory reporting subjects, increase investment, accelerate the speed of comprehensive promotion and improve the system construction, supporting minor victims to get timely relief. According to the statistics of Girls Protection, among the 750 victims of child sexual abuse cases publicly reported in 2018, 718 girls were sexually abused, accounting for $95.74 \%$; 32 boys were sexually abused, accounting for $4.26 \%$, which is a slight decrease compared with previous years[1]. The fact that fewer cases of boys being sexually abused are publicly reported in the media does not mean boys are at lower risk. "Girls Protection has repeatedly stressed that the current situation of sexual abuse of boys is also not negligible and is more hidden; at the same time, there is a lack of relevant laws, which makes it more difficult to protect the rights of boys. For this reason, Girls Protection's child sexual abuse prevention courses are co-educational, advocating both boys and girls need protection.

With the popularization of new media, the dissemination of knowledge about children's education has evolved from offline to online. Parents can gain children's sex education knowledge through the Internet, and the knowledge can be used for their children's sex education counseling. 


\section{CURRENT STATE OF THE MEDIA FOR CHILDREN'S SEX EDUCATION IN CHINA}

Table1. Current state of the media for children's sex education in China

\begin{tabular}{|c|c|c|c|}
\hline Type & Name & \begin{tabular}{|l} 
Representative \\
Products
\end{tabular} & Influence \\
\hline Social'Media & $\begin{array}{l}\text { Wechat'Public--' } \\
\text { Mrs.'Figaro }\end{array}$ & $\begin{array}{l}\text { "Don't'Let'Chinese' } \\
\text { Kids'Get'all'Their' } \\
\text { Sex'Education'from } \\
\text { Porn" }\end{array}$ & $\begin{array}{l}\text { Pageviews } \\
96,000\end{array}$ \\
\hline 4 & $\begin{array}{l}\text { Wechat } \cdot \text { Public--' } \\
\text { Contemporary } \\
\text { Educator } \cdot \text { Media }\end{array}$ & $\begin{array}{l}\text { "Children's·Sex } \\
\text { Education' } \\
\text { Timetable,'a' } \\
\text { suggested· } \\
\text { collection!" }\end{array}$ & $\begin{array}{l}\text { Pageviews } \\
2,407\end{array}$ \\
\hline 4 & $\begin{array}{l}\text { Wechat' } \\
\text { Public-Xuan'Ke' } \\
\text { Ling }\end{array}$ & $\begin{array}{l}\text { "How'To'Answer' } \\
\text { the'Question' 'Where' } \\
\text { Do'I'Come'From'-.' } \\
\text { How'Important 'is' } \\
\text { Sex.Education' for' } \\
\text { Children" }\end{array}$ & $\begin{array}{l}\text { Pageviews } \\
5,173\end{array}$ \\
\hline 4 & $\begin{array}{l}\text { Wechat }{ }^{*} \\
\text { Public-Love and } \\
\text { Life }\end{array}$ & $\begin{array}{l}\text { "What'Do-You- } \\
\text { Know'about-Sex- } \\
\text { Education'in'the } \\
\text { Family" }\end{array}$ & $\begin{array}{l}\text { Pageviews } \\
4,906\end{array}$ \\
\hline 4 & $\begin{array}{l}\text { Weibo-@Professor· } \\
\text { Liu, Wenli }\end{array}$ & $\begin{array}{l}\text { "Have'You-Heard'of } \\
\text { Comprehen sive'Sex } \\
\text { Education..."--Video }\end{array}$ & $\begin{array}{l}\text { Followers } \\
220,000 \\
\text { Pageviews } \\
57,000\end{array}$ \\
\hline 4 & $\begin{array}{l}\text { Weibo-@Girls·Do· } \\
\text { not·be·Afraid·Of }\end{array}$ & $\begin{array}{l}\text { "I-Want'to'Talk'to' } \\
\text { You'about 'Another' } \\
\text { Group of ' 'Girls' } \\
\text { after-Seeing 'the' } \\
\text { Face' of the' } \\
\text { murderer 'in'Cho' } \\
\text { Doo-soon'Case" }\end{array}$ & Like·853 \\
\hline$\psi$ & $\begin{array}{l}\text { Bilibili-Hedgehog' } \\
\text { is'coming }\end{array}$ & $\begin{array}{l}\text { "Five'Minutes 'to' } \\
\text { Teach'Children'to' } \\
\text { Protect'their'Private- } \\
\text { Body'Parts.'Worth' } \\
\text { Knowing 'for'Kids' } \\
\text { and-Parents'from' } \\
\text { 3-10'Years'Old" } \\
\end{array}$ & $\begin{array}{l}\text { Pageviews } \\
35,000\end{array}$ \\
\hline 4 & $\begin{array}{l}\text { Bilibili-@Mr. } \\
\text { Banana }\end{array}$ & \begin{tabular}{|l} 
"Easy-to-understand \\
Sex-Education \\
Videos'for Kids"
\end{tabular} & $\begin{array}{l}+ \\
\text { Pageviews: } \\
327,000\end{array}$ \\
\hline
\end{tabular}

\begin{tabular}{|c|c|c|c|}
\hline & & $\psi$ & \\
\hline 4 & $\begin{array}{l}\text { Bilibili-@Shen·Du· } \\
\text { Video }\end{array}$ & $\begin{array}{l}\text { "Sex-Education'For" } \\
\text { Children:"No" } \\
\text { Naked,"No'Bad. } \\
\text { Person" }\end{array}$ & $\begin{array}{l}\text { Followers } \\
114,000 \\
\text { Pageviews } \\
35,000\end{array}$ \\
\hline 4 & $\begin{array}{l}\text { Weibo-@Human. } \\
\text { Being-Lab. }\end{array}$ & $\begin{array}{l}\text { "You'Think'It's'Too' } \\
\text { Early'for'Sex- } \\
\text { Education, but'the- } \\
\text { Bad'Guys'Won't' } \\
\text { Think'Your'Kids' } \\
\text { Are-Too'Young" }\end{array}$ & $\begin{array}{l}\text { Pageviews } \\
4,548,000\end{array}$ \\
\hline 4 & $\begin{array}{l}\text { Tiktok-@Good } \\
\text { Dad and } \text { Mom }\end{array}$ & 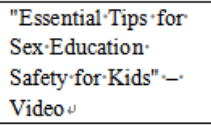 & $\begin{array}{l}\text { Pageviews' } \\
1,437,000 \\
\text { Like } 1,678\end{array}$ \\
\hline$\psi$ & $\begin{array}{l}\text { Tiktok-@Scientific· } \\
\text { Parenting }\end{array}$ & $\begin{array}{l}\text { "The Appropriate' } \\
\text { Answer'for'Children' } \\
\text { When'They'See' } \\
\text { Pads"-Video }\end{array}$ & $\begin{array}{l}\text { Followers } \\
1,461,000 \\
\text { Like } 8,174\end{array}$ \\
\hline Website & $\begin{array}{l}\text { Programmer } \\
\text { Project } \text { for }^{*} \text { Women }\end{array}$ & 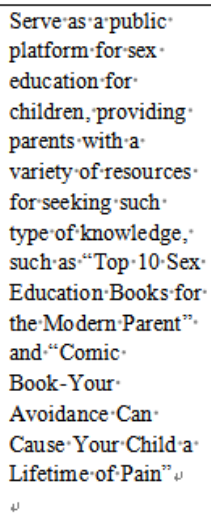 & Like'188 \\
\hline 4 & Love' in the 'Year & $\begin{array}{l}\text { "Love-in the-Year' } \\
\text { Youth-Sex- } \\
\text { Education'Lesson'1:" } \\
\text { Understanding } \cdot \text { Sex } \\
\text { Education" } \\
\end{array}$ & 4 \\
\hline \multirow[t]{2}{*}{$\psi$} & $\begin{array}{l}\text { "Sex-Education" } \\
\text { Animation:"Ding. }\end{array}$ & $\begin{array}{l}\text { "Where do I' come' } \\
\text { from" }\end{array}$ & 4 \\
\hline & $\begin{array}{l}\text { Ding 'and 'Dou'Dou' } \\
\text { life experience" }\end{array}$ & & \\
\hline 4 & $\begin{array}{l}\text { Protecting 'Dou' } \\
\text { Dou · } \\
\text { (Having 'WeChat' } \\
\text { Public'as'well) }\end{array}$ & 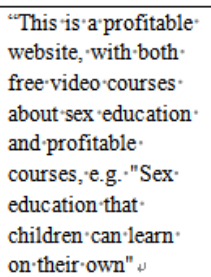 & 4 \\
\hline
\end{tabular}

As shown in table1, there are seventeen social media outlets being distributed on different social media platforms, such as WeChat Public, Weibo, BiliBili and TikTok; at the same time, there are four private media websites that publish knowledge on child sex education and provide other quality media content related to child sex education such as videos, animations, articles, child sexual abuse cases and comic books. This enables parents to use the site's resources to provide better and more correct guidance on sex education for their children. According to the above information, social media have a more objective impact on the communication of children's sexuality education and have a better viewership. However, in terms of APPs, this medium is less influential and lacking in number. In China, parents tend to use other mobile phone applications, such as 
WeChat and Weibo, so the website is not as powerful as the social media from quantity and influence view.

In terms of content quality, the table above shows $82 \%$ $(14 / 17)$ of original content, including original articles, videos and animations, and targeting both children and parents. There are 12 social media for parents, both original videos and articles, including the WeChat website "Mrs. Figaro", the microblogging platform "Girls Don't be afraid of ", the website platform "The Programmer's Project for Women", and other social media outlets. There are six social media for children, with a large proportion of content in the form of videos and animations, such as the Bilibili platform "Sex Education on Children: No naked, No bad person", the TikTok platform "Good Dad and Mom", and the series animation platform "Sex Education for Children: Ding Ding Dou dou Life Experience". The above social media only focus on a superficial knowledge of sex education and does not cover expertise in physiological structures. For example, in 2020, a Chinese netizen exposed on an online platform that her 5-year-old daughter had been sexually assaulted by a 10 -year-old boy in a bookstore, who asked the girl to remove her underwear. This case shows that lacking of sex education knowledge leaves children unaware of the abuse, which might cause a lifelong psychological trauma.

Then turning the spotlight on public interest, most of the original social media for children's sex education is supported by social funds, such as the "Ding Ding and Dou dou Life Experience", a short film jointly developed by the Guangdong Green Shoots Rural Women's Development Foundation and the Guangzhou Academy of Fine Arts in 2017. Meanwhile, there are also social media sites that monetize this, such as "Protect Dou dou". This website offers free children's sex education resources to attract readers, promoting its profitable children's sex education courses.

\section{PREMATURE SEXUALITY IN CHILDREN INCREASES THE NEED FOR SEXUALITY EDUCATION}

Child sexuality education is the process of educating children about sexual psychology, sexual physiology, sexual morality and the rule of law, it is the comprehensive cultivation of children's "sexuality"[3]. A sound child sex education helps children to grow into healthy adults, and the popularisation of child sex education can also reduce the number of child sexual abuse cases that occur in society.

As society develops and progresses, parents' attitudes towards sex education for children are variable. Some parents are accepting and open to the idea of providing sex education to children and believe that effective and correct communication of sex education to children can go a long way in helping children to protect themselves.
Other parents, however, are opposed to exposing children to such topics, believing that exposing children to sex-related topics at an early age can lead to premature adulthood and therefore to ideas that are detrimental to their healthy development. In fact, according to relevant data, sexual abuse on children is largely due to a lack of sex education and low awareness of sexual safety, which leads to their not being able to clarify whether they are being sexually abused and giving up resistance for fear of retaliation from their aggressors[2].

As a result, even though the government has issued guidelines on children's sexuality education, the lack of hardware and software for this approach has kept children sexuality education out of the existing education system and made it difficult to implement.

\section{CURRENT STATUS OF WESTERN ONLINE CHILDREN SEXUAL EDUCATION}

Kirsten J. Black, Bradley Morse, Nicole Tuitt, CeCe Big Crow, Carly Shangreau, and Carol E. Kaufman researched on how internet impacts American Indian youth's attitude toward sexual health. The research states that online program provides AIAN youth living in geographically dispersed and culturally isolated area an opportunity to aacquire sexual health knowledge. However, according to the article, there are alsp some limitations when delivering sexual information, so what they did is to combine online classes, having sixteen program delivery sites, and offline classes, cooperating the local community[4].

Some scholars did research on changes in adolescents' receipt of sex education in Spain, and they found that the proportion of adolescents talking with their parents about sex education in non-metropolitan area and in metropolitan area did not change significantly. Still 21 percent of males and 35 percent of males did not receive instruction about sex, specifically birth control, due to the lack of formal and reliable sources and guidance from parents. Such an imcomprehensive popularization about sex education triggers the declines in receipt of formal sex education and low rates of parental communication, leaving some adolescents in non-metropolitan area without instructions[5].

Azy Barak and William A. Fisher also used an approach based on the Information-MotivationBehavioral Skills model, wedding the special strengths of the Internet as a rich, interactive, individualized pedagogical tool with the strengths of well-validated behavioral science theory in order to provide effective sex education to large numbers of individuals in a very cost-effective fashion.

Studies documents recent declines in adolescents' receipt of formal sex education about a range of topics. Parents do not fill these gaps. Further efforts to increase 
access to comprehensive reproductive health information are warranted.

This study took the form of semi-structured in-depth interviews with six parents, ranging in age from 30 to 50 years old, and two sex educators, aged from 25 to 35 years old in Beijing, China. The parent interviews included both fathers and mothers. Because most sex educators in China are female, the two sex educators in this study were both female. The table below represents the interviewees for this study.

Table2. Interviews Information

\begin{tabular}{|l|l|l|l|}
\hline Number & Status & Gender & Age \\
\hline S1 & Parent & Female & 40 \\
\hline S2 & Parent & Female & 48 \\
\hline S3 & Parent & Female & 37 \\
\hline S4 & Parent & Female & 36 \\
\hline S5 & Parent & Male & 45 \\
\hline S6 & Parent & Male & 45 \\
\hline S7 & $\begin{array}{l}\text { Sex } \\
\text { educator }\end{array}$ & Female & 32 \\
\hline S8 & $\begin{array}{l}\text { Sex } \\
\text { Educator }\end{array}$ & Female & 29 \\
\hline
\end{tabular}

The researcher synchronously used a computer to record the interviewees' responses during the interviews and collated them into eight documents.

\section{REASONS FOR THE LACK OF SEX EDUCATION IN CHINA}

The following misconceptions exist when parents and schools conduct sex education.

The first is the "no-teacher theory". The second is the "triggering theory" (the belief that sex education can cause sexual stimulation and that the teaching of sex knowledge can lead to sexual problems and crimes among young children). The third one is the "blocking theory "(the view that the lack of knowledge about sex is a sign of moral purity and that it is safest to keep sex knowledge locked up for adolescents), and from the last theory is "girl before boy" theory [5].

\subsection{The influence of traditional Chinese ritual culture}

In traditional Chinese culture, there is a long-standing ancient maxim that unmarried men and women should not have intimate relationship and that women should follow specific morals and be submissive. Under the influence of such an implicit and obsolete culture, most parents find it difficult to directly talk to their children about sex and provide them with appropriate sex education, thus falling into the "blocking theory". In the interviews, some parents were more negative about talking about sex education with their children and said that "it is not necessary to discuss this subject deliberately. But if my kid comes and asks proactively, I can tell the necessary knowledge" (S2). Some parents felt that it was necessary to teach their children about sex education. For example, when one of interviewees was asked the question "how is a child born", she replied "Mum ate a seed, and the seed sprouted and you were born". From children's point of view, S1 answer was easy to understand and accessible; she did her best to show this complex process of childbirth in a story-telling way. However, this understandable "fairy-tale" approach cannot not solve all questions that children have. When this child asked followingly "where did the seeds come from" and "could I be born without dad", this parent's attitude became "I don't know how to answer such questions" (S1). If parents block children from getting sex education, children will be led to believe that the role of father in a family is unimportant, resulting the absence of the role of father in the growth of children. Therefore, such an influence of traditional ritual culture compels parents to avoid discussing the topic of sex to their children, making it somewhat impossible for children to get the full picture of the society.

\subsection{Lack of Sex Education on Parents Themselves}

There is no such thing as Comprehensive Sex Educaiton(CSE) in parents' generation. The development of media was slow at that time, so parents did not have adequate medium to access information, making them fail to accumulate adequate knowledge of sex education when they were young and to know how they could convey comprehensive sex education to their children in a scientific way in the future. Many parents are still committed to the 'no-teacher theory'. One parent said, "I didn't learn about it when I was a kid, but I naturally understand it when I grew up. So I think my child will know it at a certain age in his own way" (S4). As some parents took a passive approach to have sexuality education during their formative years, they believe that children in the digital age can still learn about it naturally. However, nowadays, the social environment is more complex, and children face more uncertainties as they grow up, so such a conservative approach to acquiring sex education is no longer appropriate for today's children.

\subsection{Neglect of the sex education curriculum in schools}

Sexuality education has not been designed as an independent curriculum, no official textbook. Instead, it is taught in the context of biology, morality and ethics (now called morality and rule of law), health education and mental health education classes. In this study, one 
sex educator interviewee states that "due to different awareness of ages parents and the deficiency of the number of teachers, it is difficult to implement the government guidance, guideline on Health Education in Primary and Secondary Schools in the teaching process" (S7). In terms of lesson period, the "Guidelines for Health Education in Primary and Secondary Schools" illustrates that sex education is included in the general framework of health education and this type of curriculum should have 6-7 lessons per semester in a flexible way, only accounting for a small proportion in the overall curriculum. This course can also be cancelled due to weather conditions. All condition makes the promotion of sex education slow. In addition, a large percentage of primary and secondary schools in China do not have the ability to hold sex education courses and recruit professional teachers. Based on a survey, $21 \%$ of the 192 primary and secondary schools in Hebei province have a full-time health education teachers, while the rest of schools use part-time or non-professional teachers to teach sex education course[8].

\subsection{Gender inequality in the development of sex education}

In homing and schooling sex education, there is a tendency to favour girls over boys, which is to focus more on self-protection and guidance for girls at the stage of physiological development. For instance, parents will tell girls some basic physiological knowledge about periods before they have reached sexual maturity, while ignoring the fact that physiological changes and education against sexual abuse for boys are equally important. In recent years, not only the rate of sexual abuse of girls increases, but the number of cases of sexual abuse of boys also shows an increase. A Meta-analysis of sexual abuse in Chinese children showed that the incidence of sexual abuse among girls was $15.3 \%$, slightly lower than international data but no significantly difference, while the rate of sexual abuse among boys was $13.8 \%$ [9], significantly higher than international data (7.6\%)[10]. In a study of Chinese urban residents aged 20-64 y $(\mathrm{F}=1519, \mathrm{M}=1475), 5.1 \%$ of males reported having had sexual contact with an adult or peer before the age of 14 years, showing a higher occurrence than females[11].

With the lack of sex education at school and at home, the new media becomes an important supplement for parents to provide sex education. Sexuality education is not only about sex and physiology, but also about sexual psychology, ethics and the legal system. Therefore, social news and animation in the new media can provide various channels for parents and children to access sexual knowledge, achieving comprehensive sexual education.

\section{THE ROLE OF NEW MEDIA IN PROMOTING THE AVAILABILITY OF SEXUALITY EDUCATION FOR CHILDREN}

\subsection{The contribution of new media to the promotion of sexuality education resources for children}

There are two main approaches to promoting access to child sexuality education in the new media. The first method is the promotion of high-quality children sexuality education resources on integrated websites, including short animation, articles, comic books, and sex education online courses for parents. The second way is the publication of sex education content for parents and children by social media accounts, which contains articles for children and analysis of cases of sexual abuse in society. The majority of parents hold positive attitude towards the existence of an application dedicated to sex education for children. During the interview, "So if there is an application that can provide suggested lessons or picture books that are tailored to specific age levels, I would actually want to do conduct sex education to my kids" (S6), said one parent Many parents felt that the new media resources will help them and their children to dive into children sex education, with one parent commenting that "I think puzzles, comic books, simple model, and cartoons are good tools we can utilize" (S6). However, in addition to the diversity of children's sex education resources, its accuracy and professionalism should also be paied more attention to."There are various channels to get sex knowledge nowadays, but not everyone acquires it for purely scientific purposes(S5). Many parents consent the practical use of new media. In the meantime, it also emphasizes the lack of professional sex education software in China, which can be a breakthrough of online sexual education in China in the future.

a. Promotion of online children sex education courses

Online sex education courses in new media provide parents with a more convenient and efficient way to access sex education. For example, Protect the DouDou, an agency combining free and profitable courses, offering parents a channel to have access to professional courses on education for children and a platform to build communication with each other. Parents can also register for their interested courses if they wish to develop more systematically. The mobile and accessible nature of the webinars provides parents with a private environment, permitting them to access effective information at the appropriate phase and location, and even to involve a global aggregation of educational resources.

b. Social news raises parents' awareness and sensitivity to child sexual abuse case. 
News showing on the Internet has given parents a more comprehensive understanding of sexual abuse cases and has helped them to raise awareness of sexual abuse and molestation prevention. Among the interviews, one parents commented: "I didn't think it was necessary to know sex at this age, but a few months ago someone told me about a 10-year-old girl who was pregnant. Her parents, even herself, didn't even know that she had been assaulted. Then I realized why this education is necessary. There are a lot of children who do not know where the boundaries of being violated are" (S4). Social media provides a public space for parents of school-age children to interact and discuss with each other, transforming cases of child sexual abuse from being underground to overt. The general direction of public opinion can also be seen in the comments on related news: the current society becomes more and more intolerant of child sexual abuse. The public, schools and parents all believe that the idea of comprehensive sex education for children should become more widely accepted.

\section{CONCLUSION}

This paper explores the contribution of China's new media environment to children's sexuality education in two ways: parents have greater and more accessible access to professional children's sexuality education resources and knowledge, and children can watch cartoons and videos on the subject of sexuality education online under the supervision of their parents. In fact, Chinese society has been working hard in recent years to dispel prejudices and misconceptions about sexuality education, and the term 'sexuality' in 'comprehensive sexuality education' Sexuality in comprehensive sexuality education encompasses both the physical and the psychological and social dimensions of sexuality, enabling children to develop positive and positive attitudes towards sexuality and to respect their own bodies and those of others, as well as to grow in knowledge, skills, attitudes and values that ensure health, well-being and dignity throughout the human life cycle. Sexuality education promotes diversity, respect, equality and inclusion, which are also beneficial to the harmonious development of society.

\section{REFERENCES}

[1] Wang,J. Report: More than half of children were repeatedly sexually assaulted, lasting up to 22 years, 2020.

https://baijiahao.baidu.com/s?id=16670137029002 $26250 \& w f r=$ spider $\&$ for $=$ pc--

[2] Xu S.Y., Li Y.W.. Personnel quality assessment [M]. Beijing: Published by Renmin University of China Press, 2018.

[3] Xie,Q, Wang,C.J. A trial discussion on the methodological innovation of children's sex education in China[J]. Innovation and Entrepreneurship Theory Research and Practice,2019,2(19):74-76.

[4] Kirsten J. B, Bradley M, Nicole Tuitt, CeCe Big Crow, Carly Shangreau, and Carol E. Kaufman. Beyond Content: Cultural Perspectives on Using the Internet to Deliver a Sexual Health Intervention to American Indian Youth, (2018) 39:59-70

[5] L.D. Lindberg et al. Changes in Adolescents' Receipt of Sex Education, 2006-2013. Journal of Adolescent Health 58 (2016) 621-627.

[6] Azy B. William A. F. Toward on Internet-driven, Theoretically-based, Innovative Approach to Sex Education. The Journal of Sex Research,(2001)

[7] Gao,Y.B, Luo B.W. The misconceptions of sex education for adolescent children[J]. Educational Research,2002(01):76-79.

[8] Zhang,X.D. Survey and suggestions on the current situation of health education in primary and secondary schools: the case of Hebei Province[J]. Educational Practice and Research, 2016( 24) : 7678.

[9] Ji K., Finkelhor, D., et al. Child Sexual Abuse in China: A Meta-analysis of 26 Studies[J]. Child Abuse \& Neglect, 2013(9):613.

[10] Stoltenborgh M., van Ijzendoorn M.H., et al. A Global Perspective on Child sexual Abuse: Metalanalysis of Prevalence Around the World[J]. Child Maltreatment, 2011(2): 79.

[11] Luo Y., Parishb W.L., et al. A Population-based Study of Childhood Sexual Contact in China : Prevalence and Longterm Consequences[J]. Child Abuse \& Neglect, 2008(32): 721. 